\title{
Post placental copper- $T$ 380A insertion after normal vaginal delivery and cesarean section and its clinical outcome
}

\author{
Jyoti Malik ${ }^{1}$, Ashima Das ${ }^{2}$, Pinki Rai ${ }^{2}$, Sibadatta Das ${ }^{3}$ \\ ${ }^{1}$ Department of Obstetrics and Gynaecology, ${ }^{2}$ Department of Anatomy, ${ }^{3}$ Department of Physiology SHKM Govt.
} Medical College, Nalhar, Haryana, India

Received: 05 May 2016

Revised: 07 June 2016

Accepted: 08 June 2016

\section{*Correspondence:}

Dr. Pinki Rai,

E-mail: pinkirai89@gmail.com

Copyright: $\odot$ the author(s), publisher and licensee Medip Academy. This is an open-access article distributed under the terms of the Creative Commons Attribution Non-Commercial License, which permits unrestricted non-commercial use, distribution, and reproduction in any medium, provided the original work is properly cited.

\begin{abstract}
Background: Post placental IUCD insertion refers to the insertion of IUD within 10 minutes of expulsion of placenta. Intra-cesarean section is insertion of IUD after removal of placenta before closure of uterine incision. The objective of this study was to study the efficacy, safety and effect on menstrual cycle, expulsion, continuation and failure rate of post-placental copper-T 380A after vaginal and cesarean birth over the period of 1 year in tertiary centre.

Methods: A total 150 women who opted for insertion of copper-T 380A within 10 minutes of expulsion of placenta whether delivered vaginally or by cesarean section, were enrolled in study. Women having past history of ectopic pregnancy or any genital tract infection or hemorrhagic disorders, uterine anomaly, chorioamnionitis, LPV $>18$ hours, unresolved $\mathrm{PPH}, \mathrm{Hb}<8 \mathrm{~g} \%$ were excluded from the study.

Results: No incidence of perforation, PID or failure of contraception was detected. Percentage of satisfaction among users after 6 weeks $91 \%, 3$ months $92.9 \%$ and 6 months $95.6 \%$.

Conclusions: Although there was high incidence of missing IUCD threads (due to coiling of thread), actual expulsion rate was far lesser. Removal rate due to menorrhagia, pain abdomen and vaginal discharge was low and 6 months continuation rate was considerably good.
\end{abstract}

Keywords: Kelly's forceps, PPIUCD insertion, Expulsion, Perforation, Failure of contraception

\section{INTRODUCTION}

Post placental IUCD insertion refers to the insertion of IUD within 10 minutes of expulsion of placenta. Intracaesarean section is insertion of IUD after removal of placenta before closure of uterine incision.

Post placental IUCD has several advantages. The woman is definitely not pregnant; she has high motivation to use contraception. Among women who have limited access to a clinician, postpartum time provides a unique opportunity to address a woman's need for contraception as the procedure is carried out by experts, and she remains under professional care post-delivery. ${ }^{1}$ It also provides protection against unwanted pregnancy without interfering with the breast feeding and avoids discomfort related to insertion. ${ }^{2}$ Bleeding due to IUCD is masked by lochia. Moreover, in a developing country like India, where a woman completes her family by the age of 30 years and where under five mortality rates high, post placental IUCD is definitely a better method than laparoscopic sterilization.

\section{METHODS}

This prospective study was done in OBGY Department of SHKM Govt. Medical College, Nalhar (Mewat), Haryana, India from the period of May 2014 to April 2015. Women were counseled in ANC OPD and labour room and encouraged to opt for post placental IUCD 
insertion. The inclusion and exclusion criteria were applied and eligible women were selected and informed consent was taken.

\section{Inclusion criteria}

Women who delivered a live baby within 10 minutes and had given informed consent for post placental IUCD insertion and did not have any contraindications as mentioned in exclusion criteria.

\section{Exclusion criteria}

- Past history of ectopic pregnancy, hemorrhagic disorder

- Known case of heart disease, diabetes

- Uterine abnormalities causing distortion

- Chorioamniotitis of LPV> 18 hours

- Hemoglobin< $8 \mathrm{gm} \%$

- Unresolved PPH

- Past or current genital tract infections or history of multiple sexual partners

- Potential infected cases of Dai handling.

\section{Methodology}

In the study group, women who had the normal vaginal delivery, post placental IUCD was inserted within 10 minutes of expulsion of placenta using Kelly's Forceps (12 Inches stainless steel, serrated curved forceps), taking all aseptic precautions. In case of cesarean section, post placental IUCD was replaced through the lower uterine segment with the help of Ring Forceps. Post placental IUCD thread was not pushed into cervical canal, and care was taken not to include the strings in suture line. Uterine incision was the closed routinely. During the post-partum period, the woman was given a post placental IUCD information leaflet and explained about the follow-up at 6 weeks, 3 months, 6 months or as soon as she notices any warning signs such as

- Foul smelling lochia

- Excessive Bleeding

- Any signs and symptoms of infection like fever, myalgia, body ache, discharge per vagina, or pain lower abdomen

- Expulsion of IUCD

During follow-up, detailed history including the menstrual cycles and regarding the warning signs was taken. Physical and pelvic examination was carried out. Post placental IUCD thread was checked and trimmed. In case post placental IUCD thread was not found on per speculum examination, Ultrasound examination was done to confirm the presence of IUCD and patient was counseled. Women were enquired about satisfaction level.

\section{RESULTS}

Out of 150 cases enrolled and studied, 16 patients were lost to follow-up at the end of 6 months. The outcomes of the study are depicted in Table 1.

Table 1: Outcomes of the study at various intervals.

\begin{tabular}{|llll|}
\hline Parameters & \multicolumn{1}{c}{ At 6 } & At 3 & At 6 \\
weeks $(\%)$ & $\begin{array}{l}\text { months }(\%) \\
\text { months }(\%)\end{array}$ \\
\hline Satisfaction level & 91.7 & 92.9 & 95.6 \\
\hline Missing thread & 25.5 & 7.2 & 4.4 \\
\hline Expulsion & 14.3 & 2.9 & 0.0 \\
\hline Menorrhagia & 11.4 & 14.5 & 7.4 \\
\hline Dysmenorrhoea & 11.4 & 5.8 & 2.9 \\
\hline PID & 0.0 & 0.0 & 0.0 \\
\hline Perforation & 0.0 & 0.0 & 0.0 \\
\hline Discontinuation & 4.3 & 5.8 & 0.0 \\
\hline Pain abdomen & 4.3 & 4.3 & 1.5 \\
\hline Vaginal discharge & 5.8 & 14.5 & 0.0 \\
\hline Failure & 0.0 & 0.0 & 0.0 \\
\hline
\end{tabular}

\section{DISCUSSION}

Post placental IUCD is a long acting, reversible contraception used in immediate post-partum period which avoids unwanted contraception without interfering with breast feeding. According to JHPIEGO and NRHM, the use of long placental forceps (Kelly's Forceps) is recommended for post placental insertion of IUCD, where the data on its usage is deficient in literature. 3 In our study, difficulty in insertion was encountered in six women, $2^{\text {nd }}$ attempt was made in all six cases and post placental IUCD was inserted successfully. No case of perforation, PID or failure of contraception was found. Although the percentage of missing threads was high at 6 weeks (18/150), only 10 had spontaneous expulsion which was reduced to Nil at 6 months. In our study, the reasons for discontinuation of post placental IUCD were non-specific pain in abdomen with dysmenorrhoea for two women, menorrhagia in two, PPH in one and two women opting for sterilization.

In the study by Shukla et al, the authors inserted $\mathrm{Cu} \mathrm{T}$ 200B in 1317 women in the immediate post-partum period. ${ }^{4}$ The complicated cases were excluded. There was no immediate complication and expulsion rate at the end of follow up was 10.68 per cent. Only 11.3 per cent came for follow up at 6 months and 78 per cent came for follow up at 6 weeks. So the rate of expulsion at 6 month period was apparently not true as only 11 per cent women came for checkup. Cu T 200B has been used because this study was conducted in 1995-2000. There is a need for randomized controlled trials to compare the safety and efficacy of IUD (Copper T 380A) when inserted at different times.

It has been observed that expulsion rates vary according to clinician's skill in post-placental insertion of IUD. ${ }^{5}$ 
Thus additional training for post-partum insertion of IUD should be provided to the clinicians and the special kit for the same should be provided to the health centers where deliveries are conducted. ${ }^{6}$

According to medical eligibility criteria $2009,4^{\text {th }}$ edition, immediate post-placental insertion of Copper $(\mathrm{Cu} T)$ is recommended in breast feeding as well as non-breast feeding mothers. ${ }^{7}$ It is safe and effective. Insertion after delivery of the placenta is associated with lower expulsion rates than delayed post-partum insertion. Additionally, post-placental placement at the time of caesarean section has lower expulsion rates than postplacental vaginal insertions. Insertion complications of perforation and infection are not increased by IUD placement at any time during the post-partum period. ${ }^{8,9}$

\section{CONCLUSION}

In our study, we concluded that insertion $\mathrm{f}$ post placental IUCD immediately following delivery is an effective, safe, convenient, low cost and long term reversible method of post-partum contraception. We recommend that post placental IUCD insertion should be routinely offered to all eligible post-partum women undergoing institutional deliveries, we also recommend that studies of larger size and longer period of follow-up may be undertaken to further evaluate its safety and clinical outcome.

\section{Funding: No funding sources}

Conflict of interest: None declared

Ethical approval: All procedures followed were in accordance with the ethical standards of the responsible committee on human experimentation (Institutional and National) and with the Helsinki Declaration of 1975 as revised in 2008.

\section{REFERENCES}

1. Kapp N, Curtis KM. Intrauterine device insertion during the postpartum period: a systematic review. Contraception. 2009;80:327-36.

2. Grimes DA, Lopez LM, Schulz KF, Van Vliet HAAM, Stanwood NL. Immediate post-partum insertion of intrauterine devices. Cochrane Database Syst Rev. 2003;(1): CD003036.

3. John Hopkins Programme for International Education in Obstetrics and Gynecology (JHPIEGO), USA, 2010. Available at http://web.jhu.edu/administration/provost/past_provo sts.

4. Shukla M, Qureshi S, Chandravati. Post-plecental intrauterine device insertion - a five year experience at a tertiary care centre in north India. Indian $\mathrm{J}$ Med Res. 2012;136:432-5.

5. Thiery M, Van Kets H, Van Der Pas H. Immediate postplacental IUD insertion: the expulsion problems. Contraception. 1985;31:331-49.

6. Muthal-Rathore A. Immediate postpartum insertion for intrauterine devices: RHL commentary. The WHO Reproductive Health Library. Geneva WHO 2010. Available at http://apps.who.int/rhl/archives/cd003036_muthalrat horea_com/en/index.html\#.

7. Medical eligibility criteria for contraceptive use. $4^{\text {th }}$ ed. Department of Reproductive Health, WHO; 2009. Available at http://apps.who.int/iris/bitstream/ 10665/181468/1/9789241549158_eng.pdf.

8. Welkovic S, Costa LO, Faundes A, de Alentar Ximenes R, Costa CF. Post-partum bleeding and infection after post-placental IUD insertion. Contraception. 2001;63:155-8.

9. Zhou SW, Chi IC. Immediate postpartum IUD insertions in a Chinese hospital: a two year followup. Int J Gynaecol Obstet. 1991;35:157-64.

Cite this article as: Malik J, Das A, Rai P, Das S. Post placental copper-T 380A insertion after normal vaginal delivery and cesarean section and its clinical outcome. Int J Reprod Contracept Obstet Gynecol 2016;5:2254-6. 